University of Wollongong

Research Online

Australian Institute for Innovative Materials -

Papers

Australian Institute for Innovative Materials

$1-1-2018$

\title{
Plasma-Induced Amorphous Shell and Deep Cation-Site S Doping Endow TiO2 with Extraordinary Sodium Storage Performance
}

\author{
Hanna He \\ University of Wollongong, Central South University \\ Dan Huang \\ Guangxi University \\ Wei Kong Pang \\ University of Wollongong, wkpang@uow.edu.au \\ Dan Sun \\ Central South University \\ Qi Wang \\ Central South University
}

See next page for additional authors

Follow this and additional works at: https://ro.uow.edu.au/aiimpapers

Part of the Engineering Commons, and the Physical Sciences and Mathematics Commons

Research Online is the open access institutional repository for the University of Wollongong. For further information contact the UOW Library: research-pubs@uow.edu.au 


\title{
Plasma-Induced Amorphous Shell and Deep Cation-Site S Doping Endow TiO2 with Extraordinary Sodium Storage Performance
}

\author{
Abstract \\ Structural design and modification are effective approaches to regulate the physicochemical properties of \\ TiO 2, which play an important role in achieving advanced materials. Herein, a plasma-assisted method is \\ reported to synthesize a surface-defect-rich and deep-cation-site-rich S doped rutile TiO 2 (R-TiO 2- $\mathrm{x}-\mathrm{S}$ ) \\ as an advanced anode for the $\mathrm{Na}$ ion battery. An amorphous shell $(\approx 3 \mathrm{~nm})$ is induced by the $\mathrm{Ar} / \mathrm{H} 2$ \\ plasma, which brings about the subsequent high $S$ doping concentration $(\approx 4.68$ at $\%)$ and deep doping \\ depth. Experimental results and density functional theory calculations demonstrate greatly facilitated ion \\ diffusion, improved electronic conductivity, and an increased mobility rate of holes for R-TiO 2- $\mathrm{x}-\mathrm{S}$, which \\ result in superior rate capability (264.8 and $128.5 \mathrm{mAh} \mathrm{g} \mathrm{-1}$ at 50 and $10000 \mathrm{~mA} \mathrm{~g} \mathrm{-1}$, respectively) and \\ excellent cycling stability (almost $100 \%$ retention over 6500 cycles). Such improvements signify that \\ plasma treatment offers an innovative and general approach toward designing advanced battery \\ materials.
}

\section{Keywords}

sodium, extraordinary, tio2, endow, doping, storage, cation-site, performance, deep, shell, amorphous, plasma-induced

Disciplines

Engineering | Physical Sciences and Mathematics

\section{Publication Details}

He, H., Huang, D., Pang, W., Sun, D., Wang, Q., Tang, Y., Ji, X., Guo, Z. \& Wang, H. (2018). Plasma-Induced Amorphous Shell and Deep Cation-Site S Doping Endow TiO2 with Extraordinary Sodium Storage Performance. Advanced Materials, 30 (26), 1801013-1-1801013-8.

\section{Authors}

Hanna He, Dan Huang, Wei Kong Pang, Dan Sun, Qi Wang, Yougen Tang, Xiaobo Ji, Zaiping Guo, and Haiyan Wang 
DOI: $10.1002 /$ ((please add manuscript number))

Article type: Communication

\section{Plasma-induced amorphous shell and deep cation-site $\mathrm{S}$ doping endow $\mathrm{TiO}_{2}$ with extraordinary sodium storage performance}

Hanna He, Dan Huang, Weikong Pang, Dan Sun, Qi Wang, Yougen Tang*, Xiaobo Ji, Zaiping Guo*, Haiyan Wang*

H. He, D. Sun, Q. Wang, Prof. Y. Tang, Prof. X. Ji, Prof. H. Wang

College of Chemistry and Chemical Engineering, Central South University, Changsha 410083, P. R. China

E-mail: wanghy419@126.com (H. Wang); ygtang@csu.edu.cn (Y. Tang)

H. He, Dr. W. Pang, Prof. Z. Guo

Institute for Superconducting \& Electronic Materials, University of Wollongong, Wollongong, New South Wales 2522, Australia

E-mail: zguo@uow.edu.au

Prof. Z. Guo

School of Mechanical, Materials, Mechatronics, and Biomedical Engineering, University of

Wollongong, Wollongong, New South Wales 2500, Australia

Prof. D. Huang

Guangxi Key Laboratory for Relativistic Astrophysics, Guangxi Colleges and Universities Key Laboratory of Novel Energy Materials and Related Technology, Guangxi Novel Battery Materials Research Center of Engineering Technology, School of Physical Science and Technology, Guangxi University, Nanning 530004, P. R. China

Keywords: sodium ion battery; titanium dioxide; deep cation-site S doping; amorphous shell; rate performanc 


\section{WILEY-VCH}

Structural design and modification are effective approaches to regulate the physicochemical properties of $\mathrm{TiO}_{2}$, which play an important role in achieving advanced materials. Herein, we report a plasma-assisted method to synthesize a surface-defect-rich and deep-cation-site-rich $\mathrm{S}$ doped rutile $\mathrm{TiO}_{2}\left(\mathrm{R}-\mathrm{TiO}_{2-x}-\mathrm{S}\right)$ as an advanced anode for the $\mathrm{Na}$ ion battery. An amorphous shell $(\sim 3 \mathrm{~nm})$ is induced by the $\mathrm{Ar} / \mathrm{H}_{2}$ plasma, which brings about the subsequent high $\mathrm{S}$ doping concentration ( 4.68 at. \%) and deep doping depth. Experimental results and density functional theory calculations demonstrate greatly facilitated ion diffusion, improved electronic conductivity, and an increased mobility rate of holes for $\mathrm{R}-\mathrm{TiO}_{2-x}-\mathrm{S}$, which result in superior rate capability $\left(264.8 \mathrm{mAh} \mathrm{g}^{-1}\right.$ and $128.5 \mathrm{mAh} \mathrm{g}^{-1}$ at $50 \mathrm{~mA} \mathrm{~g}^{-1}$ and $10000 \mathrm{~mA} \mathrm{~g}^{-1}$, respectively) and excellent cycling stability (almost 100\% retention over 6500 cycles). Such improvements signify that plasma treatment offers an innovative and general approach toward designing advanced battery materials. 


\section{WILEY-VCH}

Sodium ion batteries (SIBs) have attracted great research enthusiasm for scalable stationary energy storage systems due to the low cost and natural abundance of sodium resources, and its similar intercalation mechanism to lithium ion batteries (LIBs). ${ }^{[1]}$ Nevertheless, the much larger ionic radius of sodium $(1.02 \AA)$ than that of lithium $(0.76 \AA)$ makes it more difficult to find suitable electrode materials for effective and durable accommodation of sodium ions. Titanium dioxide $\left(\mathrm{TiO}_{2}\right)$ has received enormous attention as a sodium ion battery anode due to its high theoretical capacity $\left(335 \mathrm{mAh} \mathrm{g}^{-1}\right)$, suitable sodiation pathways and low volume expansion upon sodiation. ${ }^{[2,3]}$ The low sodium ion mobility within pristine $\mathrm{TiO}_{2}$ crystal, however, together with its poor intrinsic conductivity, originating from its large band gap $(3.0 \mathrm{eV})$, leads to the preferential location of the available active sites for high-rate sodium intercalation in the surface layer, resulting in inferior sodium storage performance. ${ }^{[4-6]}$

Very recently, many experimental results have revealed that doping $\mathrm{TiO}_{2}$ with heteroatoms could introduce sufficient defects and oxygen vacancies, which would result in significantly facilitated intrinsic electronic conductivity. ${ }^{[7,8]}$ Consequently, various forms of heteroatom-doped $\mathrm{TiO}_{2}$ (such as with $\mathrm{N},{ }^{[8,9]} \mathrm{B},{ }^{[7]} \mathrm{Nb},{ }^{[10]} \mathrm{Sn},{ }^{[11]}$ and $\mathrm{S}^{[12]}$ ) have been synthesized, and enhanced sodium storage performance has been demonstrated. Theoretical calculations suggested, however, that only when the concentration of dopant is sufficiently high to continuously induce a vacancy band of electronic states in the band gap of $\mathrm{TiO}_{2}$, can any significant improvement of the electronic conductivity be achieved. ${ }^{[13]}$ Otherwise, a low dopant level can only introduce localized oxygen vacancy states, which would destroy the electronic mobility and dramatically impair the efficiency of doping. ${ }^{[14]}$ Moreover, it has been shown computationally that deep cation-site doping could narrow the band gap of $\mathrm{TiO}_{2}$ to a large extent, resulting in higher intrinsic electronic conductivity. ${ }^{[14,15]}$ The doping depth is always confined to near the surface, however, and the doping concentration is relatively low due to the limited solubility of substitutional dopants in bulk 


\section{WILEY-VCH}

$\mathrm{TiO}_{2}$. In addition, relevant work with respect to the effects of deep cation-site doping on the sodium storage performance of $\mathrm{TiO}_{2}$ is currently lacking. Therefore, it is desirable to achieve high doping concentrations together with deep doping in bulk $\mathrm{TiO}_{2}$.

Interestingly, several recent pioneering works have shown that designing materials with amorphous features could accelerate ionic and electronic diffusion. ${ }^{[16]}$ Siegel et al. demonstrated that amorphous $\mathrm{Li}_{2} \mathrm{O}_{2}$ features ionic conductivity that is larger by 12 orders of magnitude compared to its crystalline counterpart. $^{[17]}$ Surface amorphous (SA)$\mathrm{TiO}_{2} @$ graphene composite exhibited vastly improved lithium storage performance compared to crystalline $\mathrm{TiO}_{2}{ }^{[18]}$ Typically, defects and oxygen vacancies would be induced during the introduction of amorphous phase. ${ }^{[18,19]}$ The defect-rich amorphous phase would improve the solubility of dopant atoms, consequently achieving not only a higher doping level, but also enhanced ion and electron diffusion. ${ }^{[19,20]}$ Inspired by the above considerations, it is believed that combining a high concentration of deep cation-site dopants with surface amorphization would be a promising strategy to improve the anodic performance of $\mathrm{TiO}_{2}$ for sodium ion batteries.

Herein, a unique surface-defect-rich and deep $\mathrm{S}$-cation doped $\mathrm{TiO}_{2}\left(\mathrm{R}^{-} \mathrm{TiO}_{2-x}-\mathrm{S}\right)$ was synthesized through a simple hydrolysis method followed by a plasma-assisted S doping strategy. An ultrathin amorphous shell generated by $\mathrm{Ar} / \mathrm{H}_{2}$ plasma treatment, followed by a high-concentration $(\sim 4.68$ at. \%) of $\mathrm{S}$ and deep $\mathrm{S}$ doping, gave rise to greatly improved intrinsic electronic conductivity and enhanced sodium ion diffusion in $\mathrm{R}-\mathrm{TiO}_{2-x}-\mathrm{S}$. DFT calculation has shown that cation doping is more advantageous for reducing the band gap and accelerating the mobility rate of holes at the same doping concentration than anion doping. The advantages of the designed structure result in high reversible capacity, and outstanding long-term cycling stability and rate capability of $\mathrm{R}-\mathrm{TiO}_{2-x}-\mathrm{S}$ in SIBs.

We first synthesized $\mathrm{TiO}_{2}$ precursor through a simple hydrolysis method. Then, the $\mathrm{TiO}_{2}$ precursor was treated with $\mathrm{Ar} / \mathrm{H}_{2}$ plasma to form a thin amorphous $\mathrm{TiO}_{2-x}$ shell. This 


\section{WILEY-VCH}

amorphous shell possesses a large amount of defects (stable $\mathrm{Ti}^{3+}$ and oxygen vacancies), becoming more accessible to dopant atoms. ${ }^{[19]} \mathrm{S}$ vapour, which is produced by the sublimation of $\mathrm{S}$ powder on the upstream side of the furnace (Figure S1, Supporting Information), subsequently doped into the defect-rich and surface loosely packed $\mathrm{TiO}_{2-x}$, ensuring a high S doping concentration ( 4.68 at. \%) and deep S doping depth, thus forming the yellowish-brown $\mathrm{R}_{-} \mathrm{TiO}_{2-x}-\mathrm{S}$ (Figure 1). For comparison, light-yellow $\mathrm{R}-\mathrm{TiO}_{2}-\mathrm{S}$ (doping content of $\sim 0.87$ at. \%) and light-gray defect-rich $\mathrm{R}_{-} \mathrm{TiO}_{2-x}$ were also prepared in similar way but without plasma treatment $\left(\mathrm{R}-\mathrm{TiO}_{2}-\mathrm{S}\right)$ or without $\mathrm{S}$ doping $\left(\mathrm{R}-\mathrm{TiO}_{2-x}\right)$ (Figure 1$)$. (The details are included in the Experimental section in Supporting Information.)

The morphology of all the samples was characterized by scanning electron microscopy (SEM). The pristine $\mathrm{R}-\mathrm{TiO}_{2}$ shows a flower-like morphology with an average particle size of about $500 \mathrm{~nm}$, and the crystal size and morphology are well maintained after $\mathrm{Ar} / \mathrm{H}_{2}$ plasma treatment and S doping (Figure S2a-2d, Supporting Information). The transmission electron microscope (TEM) images show that the size of each petal is about $250 \mathrm{~nm}$ in length and 50 $\mathrm{nm}$ in width (Figure S2e-2h, Supporting Information). From the magnified TEM images, we can see that the flower is heavily populated with nanopores about 10-12 $\mathrm{nm}$ in size (Figure S3a and 3b, Supporting Information), which is further supported by the pore size distribution results (Figure $\mathrm{S} 3 \mathrm{a}$ and $\mathrm{S} 3 \mathrm{~b}$, Supporting Information). The BET surface areas for $\mathrm{R}-\mathrm{TiO}_{2}$ and $\mathrm{R}-\mathrm{TiO}_{2-\mathrm{x}} \mathrm{S}$ are 46.33 and $53.15 \mathrm{~m}^{2} \mathrm{~g}^{-1}$, respectively. Interestingly, the specific surface area of $\mathrm{R}-\mathrm{TiO}_{2-\mathrm{x}}-\mathrm{S}$ increased after plasma treatment, which is in good agreement with Xu's work. ${ }^{[21]}$ They proved that the plasma treatment could effectively engrave NiO nanosheets with more exposed surface area per unit mass. Thus, the increased surface area of $\mathrm{R}-\mathrm{TiO}_{2-\mathrm{x}}-\mathrm{S}$ in our work may be caused by the surface amorphization with the assistant of plasma. The porous flower-like morphology and higher surface area of $\mathrm{R}-\mathrm{TiO}_{2-\mathrm{x}}-\mathrm{S}$ could effectively prevent aggregation and improve the electrode/electrolyte contact, leading to better electrochemical properties. ${ }^{[4,22]}$ 


\section{WILEY-VCH}

High resolution TEM (HRTEM) images of all the samples are shown in Figure 2a-d. R$\mathrm{TiO}_{2}$ displays a highly crystalline structure with a lattice $d$-spacing of $0.16 \mathrm{~nm}$, corresponding to the (220) lattice planes of rutile phase (Figure 2a). After S doping, a very thin amorphous shell less than $1 \mathrm{~nm}$ in thickness appears on the $\mathrm{R}-\mathrm{TiO}_{2}-\mathrm{S}$ particles (Figure $2 \mathrm{~b}$ ). Notably, the $\mathrm{Ar} / \mathrm{H}_{2}$ plasma treatment results in much more obvious amorphous shells $(\sim 3 \mathrm{~nm})$ for $\mathrm{R}-\mathrm{TiO}_{2-x}$ (Figure 2c), and the shell thickness is well retained after the $S$ incorporation (Figure $2 \mathrm{~d}$ ). The element mapping images show homogeneous distributions of $\mathrm{Ti}, \mathrm{O}$, and $\mathrm{S}$ elements in the R$\mathrm{TiO}_{2}-\mathrm{S}$ and $\mathrm{R}-\mathrm{TiO}_{2-x}-\mathrm{S}$ (Figure $2 \mathrm{e}-\mathrm{f}_{3}$ ). The energy dispersive $\mathrm{X}$-ray spectroscopy (EDX) results demonstrate a much higher doping concentration in $\mathrm{R}^{-\mathrm{TiO}_{2-x}-\mathrm{S}}(4.79$ at. \%) than in $\mathrm{R}-$ $\mathrm{TiO}_{2}-\mathrm{S}(0.76$ at. \%), suggesting that the loosely packed defect rich amorphous shell is beneficial for the $\mathrm{S}$ diffusion into $\mathrm{TiO}_{2}$ crystal, consequently resulting in a higher doping concentration in $\mathrm{R}^{-\mathrm{TiO}_{2-x}-\mathrm{S}}$ (Figure $\mathrm{S} 5 \mathrm{a}$ and $\mathrm{S} 5 \mathrm{~b}$, Supporting Information).

The X-ray diffraction (XRD) patterns of all the samples (Figure S6a, Supporting Information) show mixed phases with the main diffraction peaks in accordance with the rutile phase (JCPDS\#21-1276, P42/mnm (136)), and a few peaks labelled with stars correspond to the anatase phase (JCPDS\#21-1272, 141/amd (141)). The effects of S doping on the phase and crystal structure of the $\mathrm{TiO}_{2}$ were further investigated by Rietveld refinement, and the lattice parameters are summarized in Table S1, Supporting Information. Interestingly, compared to the pristine $\mathrm{R}_{-\mathrm{TiO}}(a=b=4.5966 \AA$ and $c=2.9597 \AA$ ) (Figure S6b, Supporting Information), the lattice parameters of $\mathrm{R}-\mathrm{TiO}_{2}-\mathrm{S}$ are increased $(a=b=4.5982 \AA$ and $c=$ $2.9602 \AA)$, while those for $\mathrm{R}-\mathrm{TiO}_{2-x}-\mathrm{S}$ are decreased $(a=b=4.5939 \AA$ and $c=2.9576 \AA)$ after the different $\mathrm{S}$ doping processes (Figure $2 \mathrm{~g}$ and Figure $2 \mathrm{~h}$ ). When $\mathrm{S}$ occupies $\mathrm{O}$ sites and forms Ti-S bonds, the lattice parameters would increase. Deeper substitution on Ti sites, however, would form S-O bonds, leading to decreased lattice parameters. Therefore, we can deduce that the $\mathrm{S}$ atoms mainly occupy the $\mathrm{O}$ sites in $\mathrm{R}-\mathrm{TiO}_{2}-\mathrm{S}$, while they tend to replace $\mathrm{Ti}$ on the deeper Ti sites in $\mathrm{R}-\mathrm{TiO}_{2-x}-\mathrm{S}$ after the $\mathrm{Ar} / \mathrm{H}_{2}$ plasma treatment. Raman spectra of all the 


\section{WILEY-VCH}

samples show typical Raman modes of $\mathrm{TiO}_{2}$ (Figure S6c, Supporting Information). ${ }^{[4]}$ The obvious shifting and broadening of the Raman peaks of $\mathrm{R}-\mathrm{TiO}_{2-x}$ and $\mathrm{R}-\mathrm{TiO}_{2-x}-\mathrm{S}$ indicate that the original symmetry of the $\mathrm{TiO}_{2}$ lattice is reduced, which may be due to the introduction of defects and the surface amorphization after the $\mathrm{Ar} / \mathrm{H}_{2}$ plasma treatment. ${ }^{[23]}$

The surface chemical states of all the samples were further investigated by X-ray photoelectron spectroscopy (XPS) measurements. The survey XPS spectra (Figure S6d, Supporting Information) indicate the successful doping of $\mathrm{S}$ into $\mathrm{R}-\mathrm{TiO}_{2-x}-\mathrm{S}$ and $\mathrm{R}-\mathrm{TiO}_{2}-\mathrm{S}$. $\mathrm{Ti}^{3+} 2 \mathrm{p}_{3 / 2}(456.6 \mathrm{eV})$ and $\mathrm{Ti}^{3+} 2 \mathrm{p}_{1 / 2}(461.9 \mathrm{eV})$ peaks appear in the $\mathrm{Ti} 2 \mathrm{p}$ spectrum for $\mathrm{R}-\mathrm{TiO}_{2-}$ $x$, verifying the introduction of $\mathrm{Ti}^{3+}$ by plasma treatment (Figure S6e, Supporting Information). ${ }^{[24]}$ The Ti $2 \mathrm{p}$ and $\mathrm{O}$ 1s peaks are shifted to lower energy states, suggesting the introduction of defects as a result of $\mathrm{S}$ doping and $\mathrm{Ar} / \mathrm{H}_{2}$ plasma treatment (Figure S6e and S6f, Supporting Information). ${ }^{[4]}$ It is seen that both $\mathrm{S}^{2-}$ and $\mathrm{S}^{4+}$ species are observed in the $\mathrm{S}$ 2p spectra of $\mathrm{R}_{-} \mathrm{TiO}_{2-x} \mathrm{~S}$ and $\mathrm{R}-\mathrm{TiO}_{2}-\mathrm{S}$ (Figure $2 \mathrm{i}$ ). ${ }^{[12]}$ In the case of $\mathrm{R}-\mathrm{TiO}_{2}-\mathrm{S}$, the dominant $\mathrm{S}$ state is the $\mathrm{S}^{2-}$ species $(161.7$ and $164.0 \mathrm{eV})$, corresponding to the replacement of $\mathrm{O}^{2-}$ by $\mathrm{S}^{2-}$ in the surface, while most of the $\mathrm{S}$ states change into $\mathrm{S}^{4+}$ ions $(168.8 \mathrm{eV})$ in the $\mathrm{R}-\mathrm{TiO}_{2-x}-\mathrm{S}$ after plasma treatment. ${ }^{[25]}$ As is well known, the $S^{4+}$ in the samples may originate from possible surface absorbed $\mathrm{SO}_{3}{ }^{2-}$ or $\mathrm{S}$ substitution on $\mathrm{Ti}^{4+}$ sites in the crystal. To distinguish the $\mathrm{S}$ state, according to the method in reference, ${ }^{[26]}$ we thoroughly rinsed the $\mathrm{R}-\mathrm{TiO}_{2-x}-\mathrm{S}$ sample with diluted $\mathrm{HCl}$ and retested the XPS spectrum of $\mathrm{S} 2 \mathrm{p}$. After rinsing, the dominant state of $\mathrm{S}$ is still $\mathrm{S}^{4+}$, although the peak intensity was slightly decreased, demonstrating that the $\mathrm{S}$ mainly replaced the $\mathrm{Ti}^{4+}$ in $\mathrm{R}-\mathrm{TiO}_{2-x}-\mathrm{S}$, further confirming that the change in the XRD results is caused by the different doping sites in these two samples (Figure S7, Supporting Information). ${ }^{[12]}$ The quantitative analysis results demonstrate that the $\mathrm{S}$ contents in $\mathrm{R}-\mathrm{TiO}_{2-x^{-}}$ $\mathrm{S}$ and $\mathrm{R}-\mathrm{TiO}_{2}-\mathrm{S}$ are 4.68 at. $\%$ and 0.87 at. $\%$, respectively. It has been proved that $\mathrm{S}$ substitution for $\mathrm{Ti}^{4+}$ ions in the $\mathrm{TiO}_{2}$ crystal is more difficult than the substitution for $\mathrm{O}^{2-}$ 


\section{WILEY-VCH}

ions. ${ }^{[15,20]}$ In our case, the concentration of $S$ greatly increases, and the $S$ doping is deeper, revealing much easier doping of $\mathrm{S}$ into $\mathrm{TiO}_{2}$ after $\mathrm{Ar} / \mathrm{H}_{2}$ plasma treatment.

Time-of-flight-secondary ion mass spectrometry (TOF-SIMS) measurements were applied to detect the presence and the distribution of $\mathrm{S}$ element in all the samples. As shown in Figure 3a, R-TiO ${ }_{2}$ and $\mathrm{R}-\mathrm{TiO}_{2-x}$ show no signal of $\mathrm{S}$ element, indicating the absence of $\mathrm{S}$ in those two samples. For $\mathrm{R}-\mathrm{TiO}_{2}-\mathrm{S}$, the signal intensity of $\mathrm{S}$ is definitely present, although it remains steady as the sputtering depth increases, verifying that the S species are almost entirely confined to the surface. ${ }^{[27]}$ In the case of $\mathrm{R}-\mathrm{TiO}_{2-x}-\mathrm{S}$, the signal intensity of $\mathrm{S}$ is significantly increased, suggesting a higher concentration of S. Moreover, the intensity rises as the sputtering depth increases, indicating the deeper doping depth of $\mathrm{S}$ in $\mathrm{R}_{-} \mathrm{TiO}_{2-x}-\mathrm{S}^{[27]} \mathrm{All}$ these measurements confirm that a higher concentration and deeper doping of $S$ are achieved in $\mathrm{R}_{-}-\mathrm{TiO}_{2-x}-\mathrm{S}$ compared to $\mathrm{R}-\mathrm{TiO}_{2}-\mathrm{S}$ sample.

The presence of defects $\left(\mathrm{Ti}^{3+}\right.$ or oxygen vacancies) was further investigated by electron paramagnetic resonance (EPR) measurements (Figure 3b and c). A signal at about g-factor, $g$ $=2.003$, is observed for $\mathrm{R}-\mathrm{TiO}_{2}-\mathrm{S}, \mathrm{R}-\mathrm{TiO}_{2-x}$, and $\mathrm{R}-\mathrm{TiO}_{2-x} \mathrm{~S}$, which originates from the unpaired electrons trapped by oxygen vacancies. ${ }^{[28]}$ As shown, another signal at $g=1.996$, corresponding to $\mathrm{Ti}^{3+}$ species, appears in $\mathrm{R}-\mathrm{TiO}_{2-x}$, which can be ascribed to the partial reduction of $\mathrm{TiO}_{2}$ by $\mathrm{Ar} / \mathrm{H}_{2}$ plasma (Figure 3c). ${ }^{[24]}$ Previous work has demonstrated that incorporating foreign atoms into metal oxides would modify their defect features. ${ }^{[20,29]}$ As expected, the content of oxygen vacancies in $\mathrm{R}_{-} \mathrm{TiO}_{2-x}$ decreases significantly after $\mathrm{S}$ doping, and the signal for $\mathrm{Ti}^{3+}$ almost disappears, which may be caused by the incorporation of $\mathrm{S}$ atoms. We collected ultraviolet-visible (UV-vis) absorption spectra for all the samples, which are shown in Figure 3d. The absorption sharp edge shows an obvious red shift with a reduced band gap after plasma treatment and $\mathrm{S}$ doping, indicating enhanced electronic conductivity (Table S2, Supporting Information).

To evaluate the effects of the plasma-induced surface amorphous shell, high $\mathrm{S}$ doping 


\section{WILEY-VCH}

concentration, and deep doping depth towards improving the sodium storage performance of $\mathrm{TiO}_{2}$, the electrochemical properties of all the obtained samples were investigated. The first discharge and charge curves of all the samples at $50 \mathrm{~mA} \mathrm{~g}^{-1}$ in the voltage range of $0.01-3.0$ $\mathrm{V}$ show a similar tendency, with an obvious plateau between $1.0 \mathrm{~V}$ and $1.2 \mathrm{~V}$, which can be ascribed to the formation of solid-electrolyte interphase (SEI) films and electrolyte side reactions during the first sodiation process (Figure 4a). ${ }^{[30]}$ Clearly, all the samples exhibit excellent cycling stability (Figure 4b), and discharge capacities of 254.2, 192.7, 147.1, and 91.4 $\mathrm{mAh} \mathrm{g}^{-1}$ are obtained after 100 cycles for $\mathrm{R}-\mathrm{TiO}_{2-x}-\mathrm{S}, \mathrm{R}-\mathrm{TiO}_{2}-\mathrm{S}, \mathrm{R}-\mathrm{TiO}_{2-x}$, and $\mathrm{R}-\mathrm{TiO}_{2}$, respectively (Figure S8a, Supporting Information). As the current density increases to 200 $\mathrm{mA} \mathrm{g}^{-1}$, all the samples show a capacity increase in the initial few tens of cycles, and the capacity stays steady subsequently, which can be ascribed to the activation process. ${ }^{[2,4]}$ Obviously, both surface-amorphization and S doping have positive effects towards improving the sodium storage performance of $\mathrm{TiO}_{2}$, leading to greatly enhanced discharge capacities (223.2 $\mathrm{mAh} \mathrm{g}^{-1}$ for $\mathrm{R}_{-} \mathrm{TiO}_{2-x} \mathrm{~S}, 195.4 \mathrm{mAh} \mathrm{g}^{-1}$ for $\mathrm{R}_{-} \mathrm{TiO}_{2}-\mathrm{S}$, and $174.1 \mathrm{mAh} \mathrm{g}^{-1}$ for $\mathrm{R}_{-} \mathrm{TiO}_{2-x}$ at $200 \mathrm{~mA} \mathrm{~g}^{-1}$ ), while a discharge capacity of only $68.6 \mathrm{mAh} \mathrm{g}^{-1}$ is delivered for $\mathrm{R}-\mathrm{TiO}_{2}$ (Figure S8b, Supporting Information).

The impressive sodium storage performance of $\mathrm{R}-\mathrm{TiO}_{2-x}-\mathrm{S}$ is further highlighted by its superior rate capability. As shown in Figure 4c, $\mathrm{R}-\mathrm{TiO}_{2-x}-\mathrm{S}$ exhibits discharge capacities of 264.8, 243.7, 222.5, 183.8, 162.9, and 138.3 $\mathrm{mAh} \mathrm{g}^{-1}$ at 50, 100, 200, 500, 1000, and 2000 $\mathrm{mA} \mathrm{g}^{-1}$, respectively. Even at 5000 and $10000 \mathrm{~mA} \mathrm{~g}^{-1}$, discharge capacities of 111.3 and 101.9 $\mathrm{mAh} \mathrm{g}^{-1}$ are obtained, respectively, and $257.5 \mathrm{mAh} \mathrm{g}^{-1}$ discharge capacity is attained when the current density recovers to $50 \mathrm{~mA} \mathrm{~g}^{-1}$, indicating excellent reversibility. $\mathrm{R}-\mathrm{TiO}_{2-x}-\mathrm{S}$ has 6.3 times higher discharge capacity than $\mathrm{R}-\mathrm{TiO}_{2}$ at $10000 \mathrm{~mA} \mathrm{~g}{ }^{-1}$, although $\mathrm{R}-\mathrm{TiO}_{2}-\mathrm{S}$ and $\mathrm{R}_{-} \mathrm{TiO}_{2-x}$ only show 2.6 times and 3.2 times higher capacities, respectively. The chargedischarge curves of $\mathrm{R}-\mathrm{TiO}_{2-x}-\mathrm{S}$ at different current densities show little shifting and only a small overpotential as the current density increases, further verifying its superior rate 


\section{WILEY-VCH}

performance (Figure 4d). Electrochemical impedance spectroscopy results (EIS) for all the samples (Figure S8c, Supporting Information) demonstrate much lower charge-transfer resistance and sodium ion diffusion resistance for $\mathrm{R}_{-} \mathrm{TiO}_{2-x}-\mathrm{S}$ compared to the other samples, which may be ascribed to the increased electronic/sodium ion conductivities originating from the deep cation-site S doping and surface amorphization. Indeed, the electronic conductivities of $\mathrm{R}-\mathrm{TiO}_{2}, \mathrm{R}-\mathrm{TiO}_{2}-\mathrm{S}, \mathrm{R}-\mathrm{TiO}_{2-x}$, and $\mathrm{R}-\mathrm{TiO}_{2-\mathrm{x}}-\mathrm{S}$ were measured to be $2.78 \times 10^{-8}, 4.91 \times$ $10^{-7}, 2.93 \times 10^{-7}$, and $1.28 \times 10^{-6} \mathrm{~S} \mathrm{~cm}^{-1}$, respectively, according to the four-point probe measurement results. The rate capability of $\mathrm{R}-\mathrm{TiO}_{2-x} \mathrm{~S}$ here is superior to those of reported samples of pristine $\mathrm{TiO}_{2}$, heteroatom doped $\mathrm{TiO}_{2}$, and carbon coated $\mathrm{TiO}_{2}$ with various morphologies (Figure S8d, Supporting Information). ${ }^{[5,10,23,31]}$ Note that this present sample is without any carbon modification. The surface amorphization is likely to be one of the crucial factors behind the significantly enhanced rate capability of $\mathrm{R}-\mathrm{TiO}_{2-x}-\mathrm{S}$, which would be more favorable for sodium ion diffusion and charge transfer at high rates. ${ }^{[18]}$ Moreover, the band gap of $\mathrm{R}-\mathrm{TiO}_{2-x}-\mathrm{S}$ decreased greatly after plasma assisted $\mathrm{S}$ doping, resulting in dramatically increased intrinsic electronic conductivity. The $\mathrm{R}-\mathrm{TiO}_{2-x}-\mathrm{S}$ electrode was sequentially cycled at $10000 \mathrm{~mA} \mathrm{~g}^{-1}$ after the rate test to evaluate its long-term cycling stability at a high rate. Strikingly, it showed a discharge capacity of $128.5 \mathrm{mAh} \mathrm{g}^{-1}$ with $\sim 100 \%$ Coulombic efficiency over 6500 cycles, proving its excellent tolerance under ultra-fast insertion/extraction of sodium ions (Figure 4e). Compared with most reported $\mathrm{TiO}_{2}$-based materials (Table S3, Supporting Information), the as-prepared $\mathrm{R}-\mathrm{TiO}_{2-x}-\mathrm{S}$ electrode shows

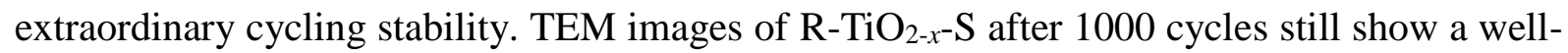
maintained flower-like morphology, confirming the superiority of this robust threedimensional structure (Figure S9, Supporting Information).

It has been proved that amorphous characteristics in active materials could accelerate their ionic and electronic diffusion. ${ }^{[18,32]}$ To verify the effects of the amorphous shell on the sodium ion diffusion, we conducted cyclic voltammetry $(\mathrm{CV})$ of $\mathrm{R}-\mathrm{TiO}_{2-x}$ (Figure S10a, 


\section{WILEY-VCH}

Supporting Information) and $\mathrm{R}-\mathrm{TiO}_{2}$ (Figure $\mathrm{S} 10 \mathrm{~b}$, Supporting Information). $\mathrm{R}-\mathrm{TiO}_{2-x}$ shows the typical electrochemical characteristics of $\mathrm{TiO}_{2}$-based anodes, with a pair of cathodic/anodic peaks at $0.76 / 0.84 \mathrm{~V}$, while those for $\mathrm{R}-\mathrm{TiO}_{2}$ are at $0.67 / 0.86 \mathrm{~V}$. Obviously, the voltage offset $\left(\Delta E_{\mathrm{p}}\right)$ of $\mathrm{R}-\mathrm{TiO}_{2-x}$ is much lower than that of $\mathrm{R}-\mathrm{TiO}_{2}$, indicating less polarization and faster electrochemical reaction kinetics after the introduction of the amorphous shell. The amorphous shell always possesses higher surface area compared to the crystalline structure, which would provide sodium ion access to the electrolyte/ $/ \mathrm{TiO}_{2}$ interface. ${ }^{[33]}$ Moreover, this amorphous shell is different from an ordinary amorphous structure. It has abundant defects, which could enhance electron transfer within the material. ${ }^{[17]}$

To understand the difference of S doping concentration and doping site in modifying the electronic structure of $\mathrm{TiO}_{2}$, we calculated the total density of states (TDOS) and the projected density of states (PDOS) of pristine, anion-site $\mathrm{S}$ doped (S@O) and cation-site $\mathrm{S}$ doped (S@Ti) rutile $\mathrm{TiO}_{2}$ with different doping concentrations using 24 -atom (4.17 at. \%), and 162atom (0.62 at. \%) rutile supercells, respectively (Figure S11, Supporting Information). Clearly, the band gap decreases after both S@O and S@Ti (Table S4, Supporting Information). For $\mathrm{S} @ \mathrm{O}$, the $\mathrm{S} 3 \mathrm{p}$ states are mixed with the valence band maximum (VBM) owing to the much higher atomic orbital energy level of the $\mathrm{S} 3 \mathrm{p}$ state than that of the $\mathrm{O} 2 \mathrm{p}$ state, thus resulting in an increased bandwidth of the valence band and a narrowed band gap (Figure 5a and 5b). S@Ti does not generate free carriers and the lone pair 3s state is present at the VBM, which also results in a decrease in the band gap (Figure 5a and 5b). The wave functions for the conduction band maximum (CBM) and VBM in 24-atom supercells of pure and S doped rutile $\mathrm{TiO}_{2}$ show similar results (Figure 5c-f). As consequence, anion-site and cation-site $\mathrm{S}$ doping strategies have two different mechanisms of action on the band structure of rutile phase, between which, cation-site doping is more advantageous for reducing the band gap at the same doping concentration (Table S4, Supporting Information). Notably, with increasing 


\section{WILEY-VCH}

doping concentration, the band gap decreases gradually from $1.54 \mathrm{eV}(0.61$ at. $\% \mathrm{~S}$ doping concentration) to $0.98 \mathrm{eV}$ (4.16 at. \% $\mathrm{S}$ doping concentration) (Table S4, Supporting Information). Moreover, the calculated results for the carrier effective masses along different axes in 24-atom supercells of pure and $\mathrm{S}$ doped $\mathrm{TiO}_{2}$ show a greatly decreased hole effective mass after $\mathrm{S}$ doping, which would increase the mobility of holes in the rutile and hence increase its intrinsic electronic conductivity (Table S5, Supporting Information). These calculation results indicate that cation-site $\mathrm{S}$ doping combined with a high doping concentration could effectively decrease the band gap and increase the mobility of holes in rutile to a greater extent, thus giving rise to better electronic conductivity.

In summary, an $\mathrm{Ar} / \mathrm{H}_{2}$ plasma-assisted $\mathrm{S}$ doping strategy was designed in this work to modify rutile $\mathrm{TiO}_{2}$. By means of prior $\mathrm{Ar} / \mathrm{H}_{2}$ plasma treatment, an ultrathin surface amorphous shell $(\sim 3 \mathrm{~nm})$ was induced, and a much higher $\mathrm{S}$ doping concentration and deep $\mathrm{S}$ doping (cation site doping) were achieved. When used as sodium ion battery anode, the as-prepared $\mathrm{R}-\mathrm{TiO}_{2-x}-\mathrm{S}$ exhibited significantly improved sodium storage performance compared with other control samples, with high discharge capacities of $264.8 \mathrm{mAh} \mathrm{g}^{-1}$ and $128.5 \mathrm{mAh} \mathrm{g}^{-1}$ at 50 $\mathrm{mA} \mathrm{g}^{-1}$ and $10000 \mathrm{~mA} \mathrm{~g}^{-1}$, respectively, together with almost $100 \%$ capacity retention at $10000 \mathrm{~mA} \mathrm{~g}^{-1}$ over 6500 cycles. This plasma-assisted $\mathrm{S}$ doped $\mathrm{TiO}_{2}$ without any carbon coating showed ultrafast sodium insertion/extraction capability and extraordinary cycling stability, which outperformed most reported $\mathrm{TiO}_{2}$ samples in the references. The experimental measurements and DFT calculations showed that the superior electrochemical performance of $\mathrm{R}-\mathrm{TiO}_{2-x}-\mathrm{S}$ can be attributed to its highly improved intrinsic electronic conductivity and accelerated sodium ion diffusion kinetics originating from the surface amorphization and deep S doping with high doping concentration. Such improvements signify that structural modification by plasma treatment is an effective strategy for improving the electrochemical performance of advanced battery materials. 


\section{WILEY-VCH}

\section{Supporting Information}

Supporting Information is available from the Wiley Online Library or from the author.

\section{Acknowledgements}

This work was financially supported by the National Natural Science Foundation of China (No. 21671200, No. 21571189, and No. 61664003), the Hunan Provincial Science and Technology Plan Project (No. 2017TP1001), the Innovation-Driven Project of Central South University (No. 2016CXS009) and the Innovation-Driven Development Foundation of Guangxi Province (Grant No. AA17204063). The authors acknowledge the Partnership for Advanced Computing in Europe (PRACE) for awarding access to the Mare Nostrum resource based in Spain at the Barcelona Supercomputing Center-Centro Nacional de Supercomputación (BSC-CNS)).

Received: ((will be filled in by the editorial staff)) Revised: ((will be filled in by the editorial staff))

Published online: ((will be filled in by the editorial staff))

\section{References}

[1] a) N. Yabuuchi, K. Kubota, M. Dahbi, S. Komaba, Chem. Rev. 2014, 114, 11636; b) X. Xiang, K. Zhang, J. Chen, Adv. Mater. 2015, 27, 5343; c) H. Gao, T. Zhou, Y. Zheng, Y. Liu, J. Chen, H. Liu, Z. Guo, Adv. Energy Mater. 2016, 6, 1601037; d) Y. Liu, Z. Tai, T. Zhou, V. Sencadas, J. Zhang, L. Zhang, K. Konstantinov, Z. Guo, H. K. Liu, Adv. Mater. 2017, 29, 1703028; e) Y. Zheng, T. Zhou, X. Zhao, W. K. Pang, H. Gao, S. Li, Z. Zhou, H. Liu, Z. Guo, Adv. Mater. 2017, 29, 1700396. f) H. Liu, X. Liu, W. Li, X. Guo, Y. Wang, G. Wang, D. Zhao, Adv. Energy Mater. 2017, 7, 1700283.

[2] Q. Gan, H. He, K. Zhao, Z. He, S. Liu , S. Yang, ACS Appl. Mater. Inter. 2018, 10, 7031.

[3] a) X. Yang, C. Wang, Y. Yang, Y. Zhang, X. Jia, J. Chen, X. Ji, J. Mater. Chem. A 2015, 3, 8800; b) S. Liu, Z. Cai, J. Zhou, A. Pan, S. Liang, J. Mater. Chem. A 2016, 4, 18278; c) H. He, 


\section{WILEY-VCH}

Q. Gan, H. Wang, G.-L. Xu, X. Zhang, D. Huang, F. Fu, Y. Tang, K. Amine, M. Shao, Nano Energy 2017, 44, 217. d) H. Liu, W. Li, D. Shen, D. Zhao, G. Wang, J. Am. Chem. Soc. 2015, $137,13161$.

[4] H. He, D. Sun, Q. Zhang, F. Fu, Y. Tang, J. Guo, M. Shao, H. Wang, ACS Appl. Mater. Inter. 2017, 9, 6093.

[5] X. Zhu, Q. Li, Y. Fang, X. Liu, L. Xiao, X. Ai, H. Yang, Y. Cao, Part. Part. Syst. Char. $2016,33,545$.

[6] Y. Wu, Y. Jiang, J. Shi, L. Gu, Y. Yu, Small 2017, 13.

[7] B. Wang, F. Zhao, G. Du, S. Porter, Y. Liu, P. Zhang, Z. Cheng, H. K. Liu, Z. Huang, ACS Appl. Mater. Inter. 2016, 8, 16009.

[8] H. A. Cha, H. M. Jeong, J. K. Kang, J. Mater. Chem. A 2014, 2, 5182.

[9] H. He, H. Wang, D. Sun, M. Shao, X. Huang, Y. Tang, Electrochim. Acta 2017, 236, 43.

[10] H. Usui, S. Yoshioka, K. Wasada, M. Shimizu, H. Sakaguchi, ACS Appl. Mater. Inter. $2015,7,6567$.

[11] D. Yan, C. Yu, Y. Bai, W. Zhang, T. Chen, B. Hu, Z. Sun, L. Pan, Chem. Commun. 2015, 51,8261 .

[12] J. Ni, S. Fu, C. Wu, J. Maier, Y. Yu, L. Li, Adv. Mater. 2016, 28, 2259.

[13] K. K. Ghuman, C. V. Singh, J. Phys.: Condens. Mat. 2013, 25, 085501.

[14] K. Yang, Y. Dai, B. Huang, J. Phys. Chem. C 2007, 111, 18985.

[15] R. Liu, X. Zhou, F. Yang, Y. Yu, Appl. Surf. Sci. 2014, 319, 50.

[16] a) J. Lee, A. Urban, X. Li, D. Su, G. Hautier, G. Ceder, Science 2014, 343, 519; b) E. Uchaker, Y. Zheng, S. Li, S. Candelaria, S. Hu, G. Cao, J. Mater. Chem. A 2014, 2, 18208; c) K. Wang, Y. Shi, B. Li, L. Zhao, W. Wang, X. Wang, X. Bai, S. Wang, C. Hao, T. Ma, Adv. Mater. 2016, 28, 1891.

[17] F. Tian, M. D. Radin, D. J. Siegel, Chem. Mater. 2014, 26, 2952.

[18] T. Zhou, Y. Zheng, H. Gao, S. Min, S. Li, H. K. Liu, Z. Guo, Adv. Sci. 2015, 2, 1500027. 


\section{WILEY-VCH}

[19] C. Yang, Z. Wang, T. Lin, H. Yin, X. Lü, D. Wan, T. Xu, C. Zheng, J. Lin, F. Huang, J. Am. Chem. Soc. 2013, 135, 17831.

[20] T. Lin, C. Yang, Z. Wang, H. Yin, X. Lü, F. Huang, J. Lin, X. Xie, M. Jiang, Energy Environ. Sci. 2014, 7, 967.

[21] L. Xu, Q. Jiang, Z. Xiao, X. Li, J. Huo, S. Wang, L. Dai, Angew. Chem. Int. Edit. 2016, $128,5363$.

[22] Y. Zhang, C. W. Foster, C. E. Banks, L. Shao, H. Hou, G. Zou, J. Chen, Z. Huang, X. Ji, Adv. Mater. 2016, 28, 9391.

[23] a) J. Chen, Z. Ding, C. Wang, H. Hou, Y. Zhang, C. Wang, G. Zou, X. Ji, ACS Appl. Mater. Inter. 2016, 8, 9142; b) H. He, Q. Zhang, H. Wang, H. Zhang, J. Li, Z. Peng, Y. Tang, M. Shao, J. Power Sources 2017, 354, 179.

[24] J. Chen, W. Song, H. Hou, Y. Zhang, M. Jing, X. Jia, X. Ji, Adv. Funct. Mater. 2015, 25, 6793.

[25] S. A. Bakar, C. Ribeiro, J. Mol. Catal. A: Chem. 2016, 421, 1.

[26] T. Ohno, M. Akiyoshi, T. Umebayashi, K. Asai, T. Mitsui, M. Matsumura, Appl. Catal. A: Gen. 2004, 265, 115.

[27] K.-S. Park, P. Xiao, S.-Y. Kim, A. Dylla, Y.-M. Choi, G. Henkelman, K. J. Stevenson, J. B. Goodenough, Chem. Mater. 2012, 24, 3212.

[28] Z. Wang, C. Yang, T. Lin, H. Yin, P. Chen, D. Wan, F. Xu, F. Huang, J. Lin, X. Xie, Adv. Funct. Mater. 2013, 23, 5444.

[29] Z. Xiao, Y. Wang, Y.-C. Huang, Z. Wei, C.-L. Dong, J. Ma, S. Shen, Y. Li, S. Wang, Energ. Environ. Sci. 2017, 10, 2563.

[30] J. Chen, G. Zou, H. Hou, Y. Zhang, Z. Huang, X. Ji, J. Mater. Chem. A 2016, 4, 12591. [31] a) Y. Zhang, C. Wang, H. Hou, G. Zou, X. Ji, Adv. Energy Mater. 2017, 7; b) A. Shoaib, Y. Huang, J. Liu, J. Liu, M. Xu, Z. Wang, R. Chen, J. Zhang, F. Wu, J. Power Sources 2017, 342, 405; c) Y. Yang, X. Ji, M. Jing, H. Hou, Y. Zhu, L. Fang, X. Yang, Q. Chen, C. E. Banks, J. 


\section{WILEY-VCH}

Mater. Chem. A 2015, 3, 5648.

[32] J. Kibsgaard, Z. Chen, B. N. Reinecke, T. F. Jaramillo, Nat. Mater. 2012, 11, 963.

[33] O. B. Chae, J. Kim, I. Park, H. Jeong, J. H. Ku, J. H. Ryu, K. Kang, S. M. Oh, Chem.

Mater. 2014, 26, 5874. 


\section{WILEY-VCH}

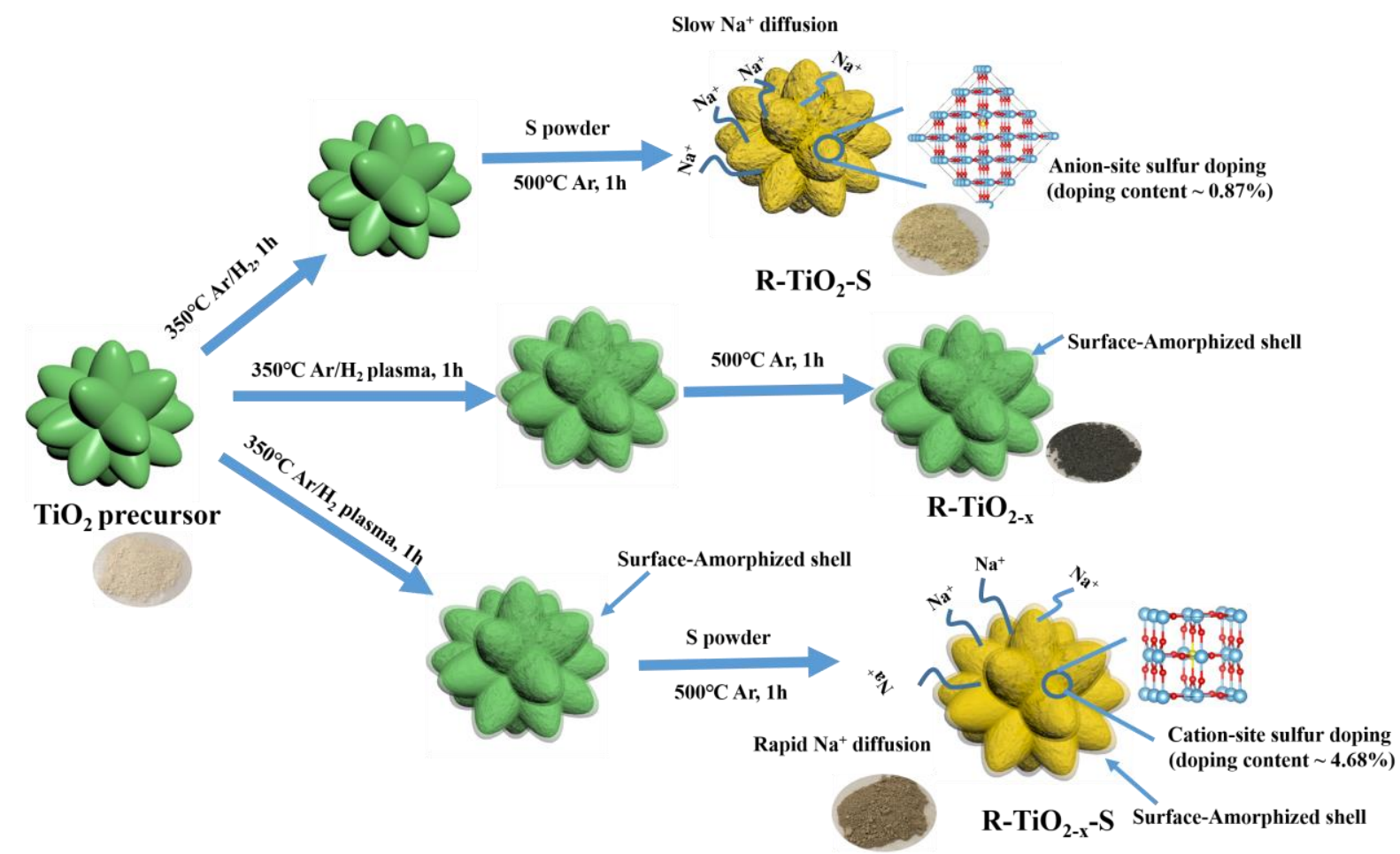

Figure 1. Synthesis process for $\mathrm{R}-\mathrm{TiO}_{2}-\mathrm{S}, \mathrm{R}-\mathrm{TiO}_{2-x}$, and $\mathrm{R}-\mathrm{TiO}_{2-x}-\mathrm{S}$. 


\section{WILEY-VCH}

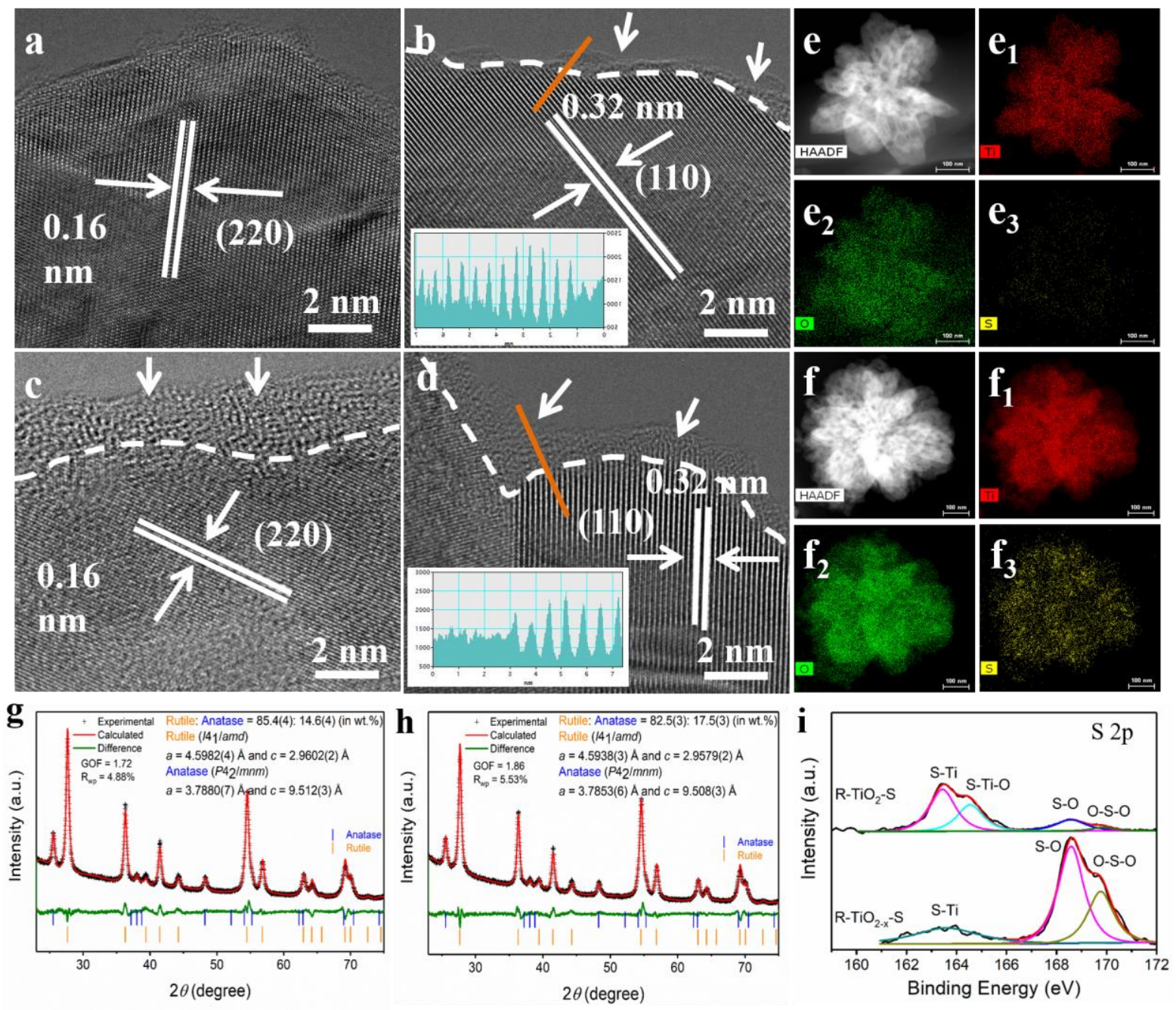

Figure 2. HRTEM images of (a) $\mathrm{R}-\mathrm{TiO}_{2}$, (b) $\mathrm{R}-\mathrm{TiO}_{2}-\mathrm{S}$, (c) $\mathrm{R}-\mathrm{TiO}_{2-x}$, and (d) $\mathrm{R}-\mathrm{TiO}_{2-x}-\mathrm{S}$.

Selected high-angle annular dark field (HAADF) images and the corresponding EDX mapping images for $\left(\mathrm{e}-\mathrm{e}_{3}\right) \mathrm{R}-\mathrm{TiO}_{2}-\mathrm{S}$ and $\left(\mathrm{f}-\mathrm{f}_{3}\right) \mathrm{R}-\mathrm{TiO}_{2-x}-\mathrm{S}$. XRD patterns for the as-prepared (g) $\mathrm{R}-\mathrm{TiO}_{2}-\mathrm{S}$ and (h) $\mathrm{R}-\mathrm{TiO}_{2-\mathrm{x}}-\mathrm{S}$ samples with Rietveld refinement. (i) S 2p XPS spectra of R$\mathrm{TiO}_{2}-\mathrm{S}$ and $\mathrm{R}-\mathrm{TiO}_{2-x}-\mathrm{S}$. The insets in (b) and (d) are the respective line profiles along the red lines. 


\section{WILEY-VCH}
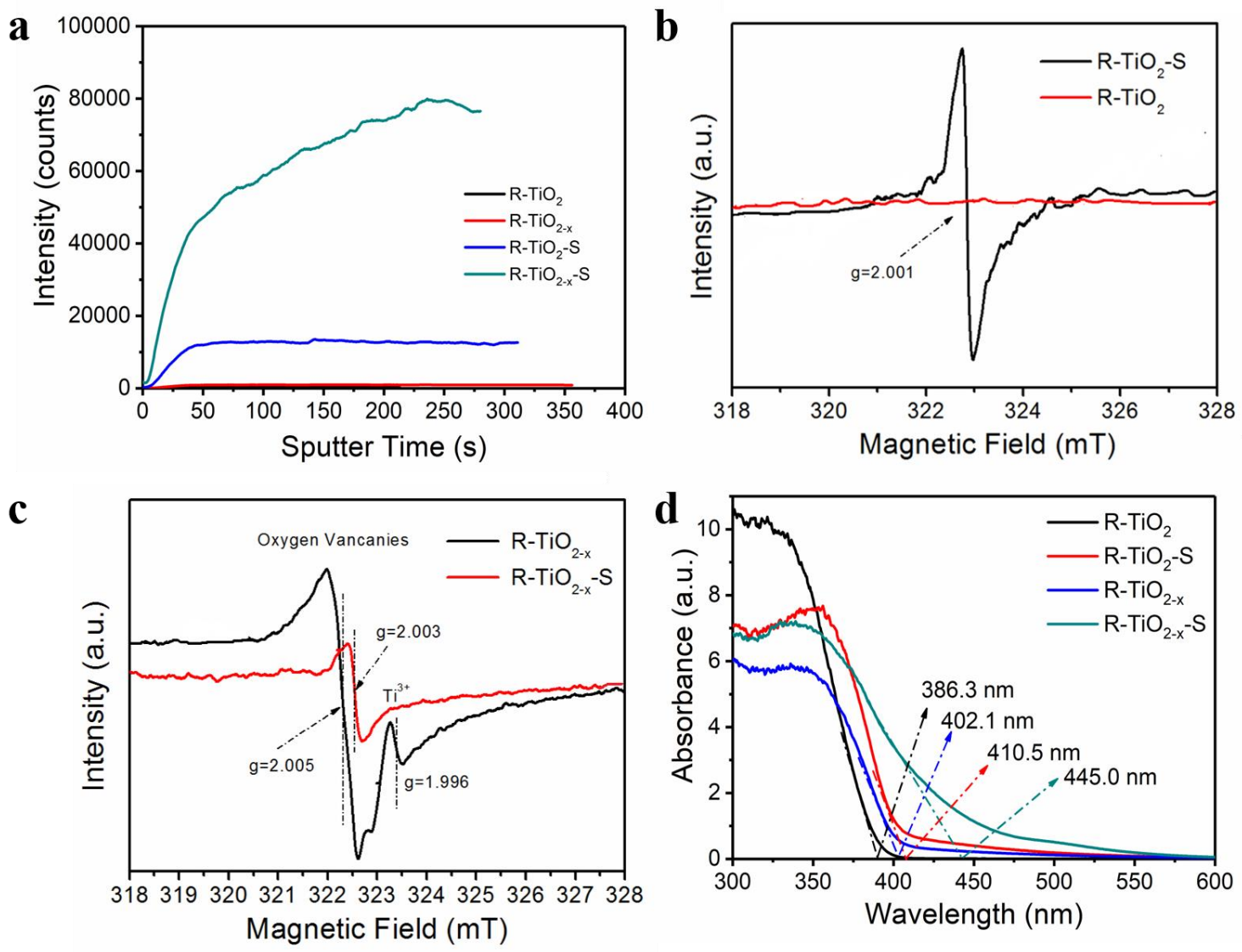

Figure 3. (a) TOF-SIMS depth profiles of $\mathrm{S}$ element for all the as-prepared $\mathrm{TiO}_{2}$ samples.

EPR images of (b) $\mathrm{R}-\mathrm{TiO}_{2}$ and $\mathrm{R}-\mathrm{TiO}_{2}-\mathrm{S}$, and (c) $\mathrm{R}-\mathrm{TiO}_{2-x}$ and $\mathrm{R}-\mathrm{TiO}_{2-x}$-S. (d) UV-vis absorption spectra of all the as-prepared $\mathrm{TiO}_{2}$ samples. 

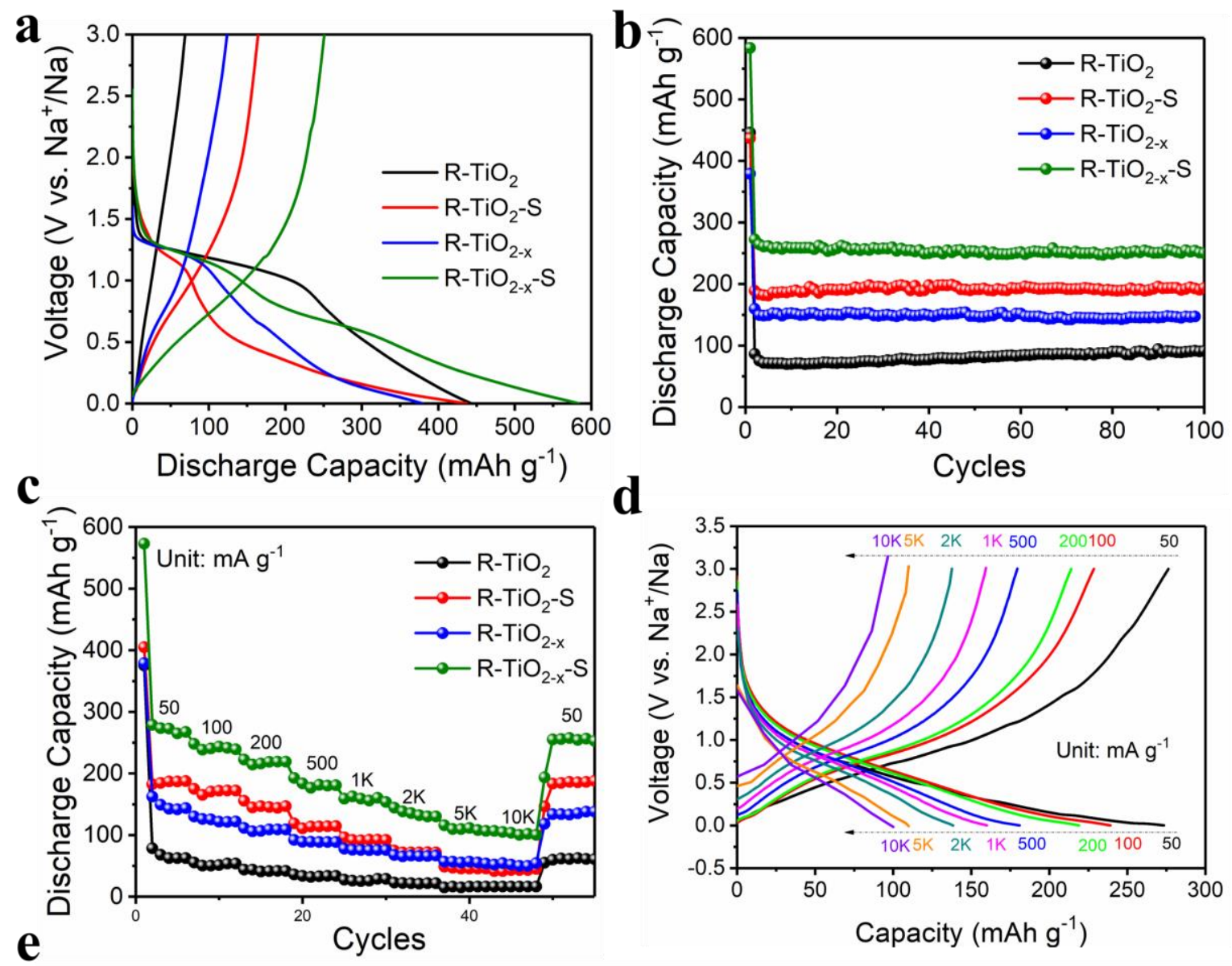

d
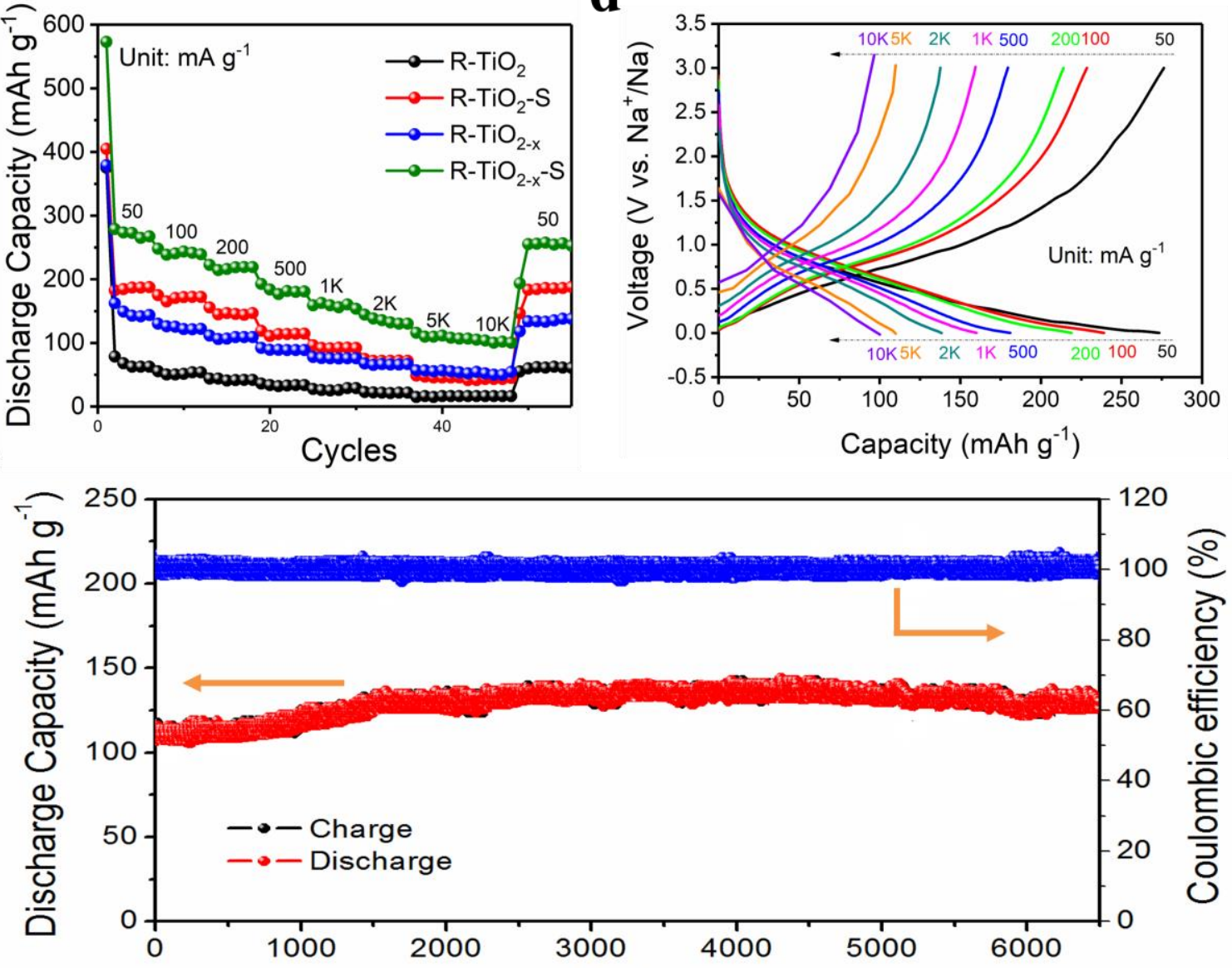

Cycles

Figure 4. (a) The initial charge/discharge curves of all the samples at $50 \mathrm{~mA} \mathrm{~g}^{-1}$ in the voltage range of 0.01-3.0 V. (b) Cycling performances of all the samples at $50 \mathrm{~mA} \mathrm{~g}^{-1}$. (c) Rate performances of $\mathrm{R}-\mathrm{TiO}_{2}, \mathrm{R}-\mathrm{TiO}_{2}-\mathrm{S}, \mathrm{R}-\mathrm{TiO}_{2-x}$, and $\mathrm{R}-\mathrm{TiO}_{2-x}-\mathrm{S}$. (d) Charge-discharge profiles of $\mathrm{R}-\mathrm{TiO}_{2-x}-\mathrm{S}$ at different rates. (e) Cycling performance and Coulombic efficiency of $\mathrm{R}-\mathrm{TiO}_{2-x}-\mathrm{S}$ at $10 \mathrm{~A} \mathrm{~g}^{-1}$ over 6500 cycles. 


\section{WILEY-VCH}

a

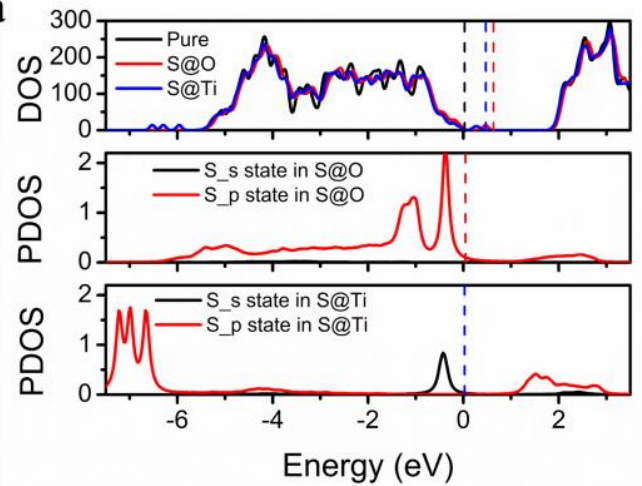

b

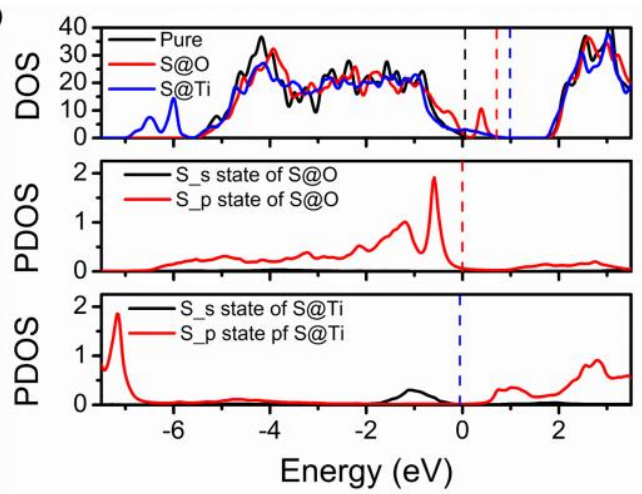

CBM

c

Pure

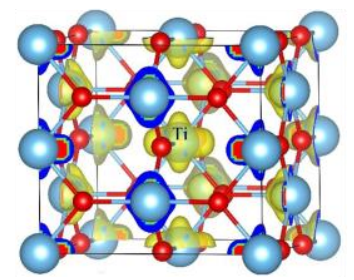

e
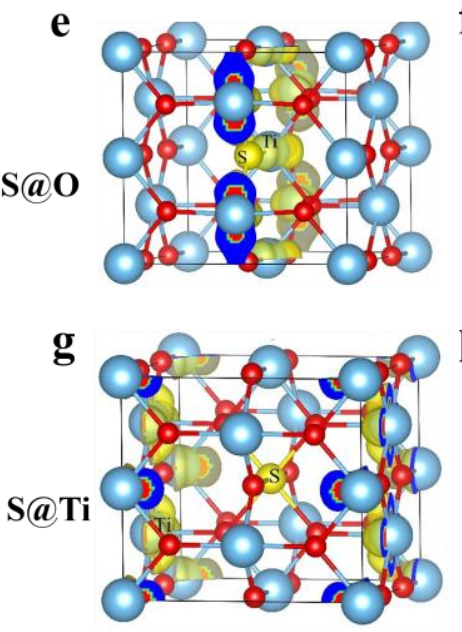

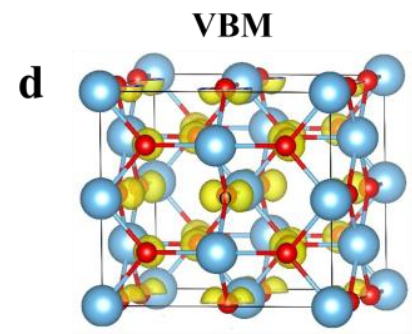

f

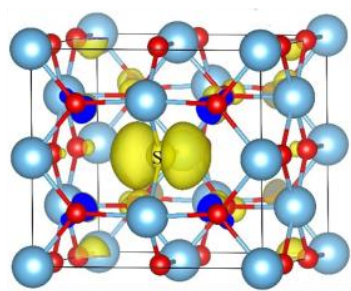

$\mathbf{h}$

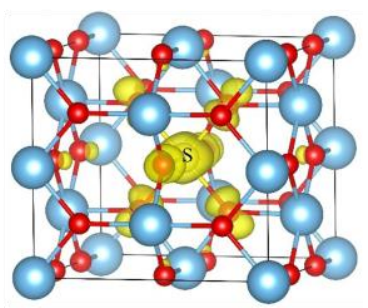

Figure 5. Calculated total density of states (TDOS) and partial density of states (PDOS) of (a) pristine rutile $\mathrm{TiO}_{2}$ and $\mathrm{S}$ doped 162 atom $\mathrm{TiO}_{2}$ supercells with different doping sites, (b) pristine rutile $\mathrm{TiO}_{2}$ and $\mathrm{S}$ doped 24 atom $\mathrm{TiO}_{2}$ supercells with different doping sites. The average potentials of the host elements far away from the dopant are used to align the DOS. Square wavefunctions for the conduction band minimum (CBM) and valence band maximum (VBM) in 24-atom supercells of (c-d) pure $\mathrm{TiO}_{2}$, (e-f) O-site $\mathrm{S}$ doped $\mathrm{TiO}_{2}(\mathrm{~S} @ \mathrm{O})$, and (g-h) Ti-site $\mathrm{S}$ doped $\mathrm{TiO}_{2}$ (S@Ti) (electron density: $\left.2 \times 10^{-5} \mathrm{e} / \AA^{3}\right)$. 


\section{WILEY-VCH}

Surface amorphous $\mathrm{TiO}_{2}$ with high content of cation site doped $\mathbf{S}$ is achieved with the assistant of plasma. Those features give rise to greatly improved intrinsic electronic conductivity and enhanced sodium ion diffusion of $\mathrm{TiO}_{2}$, leading to superior sodium storage performance. This strategy opens a new avenue to design advanced materials for energy storage system.

\section{Keyword}

sodium ion battery; titanium dioxide; deep cation-site $\mathrm{S}$ doping; amorphous shell; rate performanc

H. He, D. Huang, W. Pang, D. Sun, Q. Wang, Y. Tang*, X. Ji, Z. Guo*, H. Wang*

\section{Title}

Plasma-induced amorphous shell and deep cation-site $\mathrm{S}$ doping endow $\mathrm{TiO}_{2}$ with extraordinary sodium storage performance

TOC figure

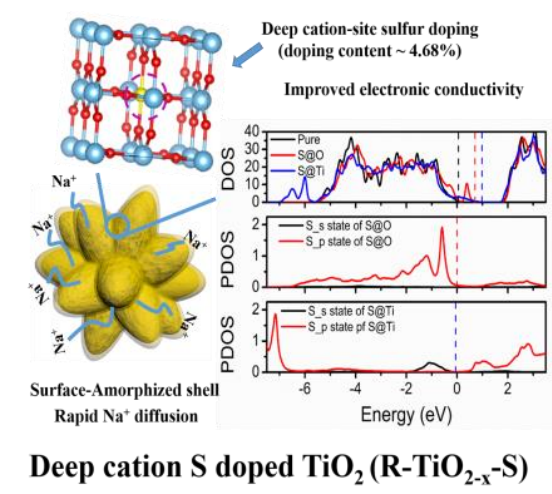

